\title{
APLICATIVO MÓVEL PARA O CONTROLE FINANCEIRO DE REPÚBLICAS UNIVERSITÁRIAS
}

\author{
Alex Junior Diniz de Souza ${ }^{1}$ \\ Leonardo Carvalho Silva ${ }^{2}$ \\ Ney Cândido da Silva Ribeiro ${ }^{3}$
}

Resumo: Com o grande avanço da era tecnológica, cresceu exponencialmente a quantidade de aplicativos móveis, onde geralmente são utilizados para facilitar as tarefas pessoais e corporativas, entre as quais se pode citar os aplicativos para controle financeiro. Neste trabalho propõe-se o desenvolvimento de uma aplicação para o controle dos gastos financeiros de integrantes de repúblicas universitárias, visando melhor controle dos gastos gerados, já que normalmente os mesmos são gerenciados manualmente e poucos usuários tem acesso as essas informações. O aplicativo será alimentado por usuários através de dados cadastrais como, despesas, quantidade de consumo, novos usuários, novas repúblicas e serviços que poderão ser oferecidos. Os dados serão processados retornando informações de maneira compartilhada de acordo com a república e o usuário. O aplicativo terá mecanismos simples para a divisão de gastos entre todos os integrantes, sendo esta feita de acordo com o percentual de consumo individual em cada despesa. Palavras-chave: Aplicativo; Despesa; Consumo; Serviço; República.

\footnotetext{
1 Discente no curso de Sistemas de Informação / Centro Universitário de Itajubá - MG - FEPI, Brasil. E-mail: alexj.diniz@outlook.com.

2 Discente no curso de Sistemas de Informação / Centro Universitário de Itajubá - MG - FEPI, Brasil. E-mail: leosilva.tecnologia@gmail.com.

3 Docente do curso de Sistemas de Informação / Centro Universitário de Itajubá - MG - FEPI, Brasil. E-mail: ney.candido.ribeiro@gmail.com.
} 